This item was submitted to Loughborough's Research Repository by the author.

Items in Figshare are protected by copyright, with all rights reserved, unless otherwise indicated.

\title{
Representation systems and undergraduate proof production: a comment on
}

\section{Weber}

PLEASE CITE THE PUBLISHED VERSION

http://dx.doi.org/10.1016/j.jmathb.2009.10.001

PUBLISHER

(C) Elsevier

VERSION

AM (Accepted Manuscript)

LICENCE

CC BY-NC-ND 4.0

\section{REPOSITORY RECORD}

Alcock, Lara, and Matthew Inglis. 2019. "Representation Systems and Undergraduate Proof Production: A Comment on Weber". figshare. https://hdl.handle.net/2134/8578. 
This item was submitted to Loughborough's Institutional Repository (https://dspace.lboro.ac.uk/) by the author and is made available under the following Creative Commons Licence conditions.

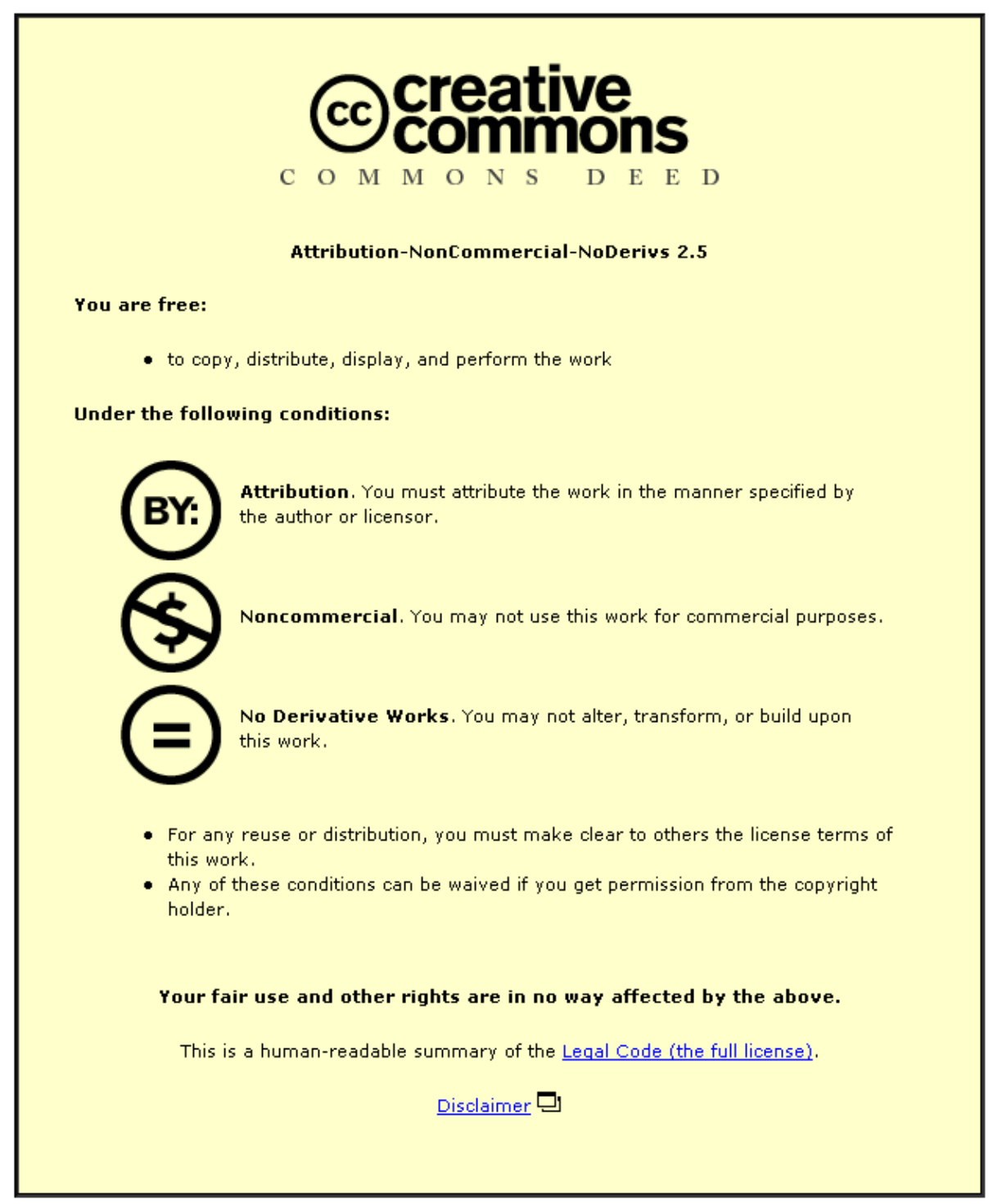

For the full text of this licence, please go to: http://creativecommons.org/licenses/by-nc-nd/2.5/ 


\title{
Representation Systems and Undergraduate Proof Production: A Comment on Weber
}

\author{
Lara Alcock \& Matthew Inglis \\ Mathematics Education Centre, Loughborough University
}

\begin{abstract}
Weber (2009) suggested that counterexamples can be generated by a syntactic proof production, apparently contradicting our earlier assertion (Alcock and Inglis, 2008). Here we point out that this ostensible difference is the result of Weber working with theoretical definitions that differ slightly from ours. We defend our approach by arguing that Weber's relies upon an as yet unspecific metric for gauging the amount of work conducted in each representation system, and that it does not recognize an important asymmetry between the status of representation systems in the context of undergraduate mathematics.
\end{abstract}

Key words:

examples, proof, reasoning, semantic, syntactic, undergraduate

In his paper, Weber (2009) presented an interesting account of the way in which Isaac, a highly successful undergraduate student with a preference for syntactic reasoning, constructed proofs in a novel mathematical setting. He played particular attention to Isaac's construction of counterexamples, and the role of examples in his reasoning more generally. Isaac's solution to several of the problems involved generating counterexamples via, according to Weber, a syntactic proof production. Consequently, Weber suggested that our earlier assertion that the generation of a counterexample (or any kind of semantic product) must necessarily involve a semantic proof production was incorrect (Alcock and Inglis, 2008). Before discussing Isaac's proof productions in detail we first briefly highlight the main ideas of the semantic/syntactic framework as we see them.

Weber and Alcock (2009) pointed out that proofs (at least at the undergraduate level) can be understood as arguments within a specific representation system, which they termed the representation system of proof, abbreviated here to RSP. However, it is possible that proofs might be generated, in part, 
using representations from outside the RSP (using, for example, specific instantiations, gestures or visual imagery). ${ }^{1}$

Weber (2009) defined two different methods of proof production:

A syntactic proof production occurs when one works predominantly within the representation system of proof [...] Alternatively, a semantic proof production occurs when much of the prover's work takes place [outside] the representation system of proof. (p. 2, our emphasis).

In contrast, in our earlier paper we had defined the two different methods of proof production subtly differently:

During a syntactic proof production the reasoner works entirely within the representation system of the to-be-proved statement, i.e. the representation system of proof. [...] During a semantic proof production the individual works, at least in part, within a different representation system to that of the to-be-proved statement. (Alcock and Inglis 2008, p. 115, our emphasis).

For Weber (2009), a semantic proof production occurs when "much of" the proof production occurs outside the RSP. In contrast, for us, such a proof production occurs when any work is done outside the RSP.

There are two reasons why we prefer our theoretical characterization. First, it does not require a solution to the difficult problem of specifying a metric for the percentage of a proof production which takes place in each representation system. And second, it respects the fundamental asymmetry between the representation systems involved in undergraduate proof production. We discuss these issues further below. However, we first explain why this definitional discrepancy accounts for the apparent disagreement between ourselves and Weber regarding the production of Isaac's counterexamples.

Isaac, the student discussed by Weber (2009), solved a problem by working syntactically to derive a statement logically equivalent to the statement he had been asked to evaluate, and then used this equivalent statement to construct a counterexample. In a categorization of example generation strategies, this sort of process was labelled analytic by Antonini (2006). Graphically, it can be represented as in Figure 1. Isaac began with a syntactic statement which he worked with syntactically, deriving a logically equivalent statement. He then constructed a counterexample to an equivalent statement by working outside the RSP (examples are typically not accepted as permitted configurations within the RSP, Alcock and Inglis 2008; Weber 2009; Weber and Alcock 2009).

$\overline{1}$ A full characterization of what a representation system consists of is discussed by Alcock and Inglis (2008); Goldin (1998); and Weber and Alcock (2009). 


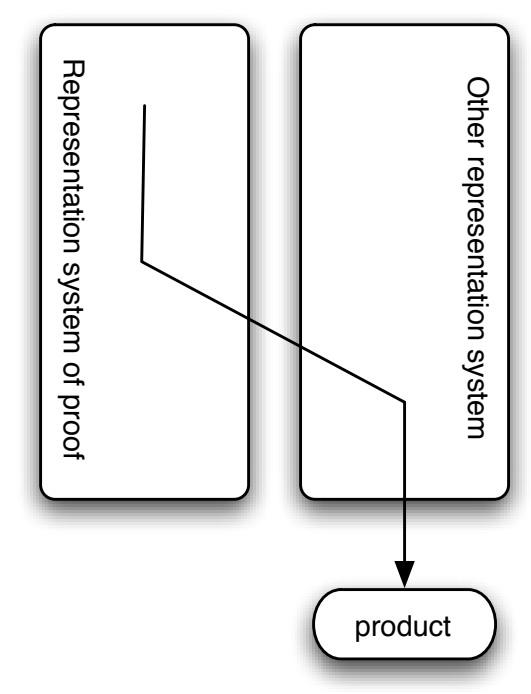

Fig. 1. Isaac's use of the different representation systems in the production of his counterexample (a semantic product).

Using our characterization of the terms, the proof production illustrated in Figure 1 is indeed semantic. It involves working with representations from outside the RSP, specifically in production of the non-RSP product. Consequently any work with a semantic product is, by necessity, semantic in our use of the term. However, using Weber's (2009) theoretical characterization the issue becomes whether or not that part of the proof production which took place outside of the RSP constituted "much of" the whole proof production. Presumably in this case Weber judged that it did not.

We argue, however, that it is unclear what metric could be specified to allow such a judgement to be made. When exploring how one could construct such a metric, a sensible first stab might be to measure the duration (in seconds, or perhaps in transcript utterances) during which the prover is working inside or outside the RSP. We believe this approach would be problematic. Even if one could measure such durations accurately, it is possible to imagine a situation in which a prover works almost entirely syntactically within the RSP, except during one short period where consideration of an insightful example provides the impetus for the correct path to a completed proof. Such a proof production would fundamentally rely upon non-RSP work, but would presumably be classified as syntactic under such a duration-based metric. An alternative might be to construct a metric that depended upon whether or not each section of reasoning conducted during the proof production was (in some sense) essential to the completed product. But it is hard to envisage how one could go about this task coherently. This is especially the case for complex proof productions which might involve multiple translations between representation systems, where essential steps may occur both in the RSP and in other representation systems, as illustrated in Figure 2. Although difficult, and perhaps impossible, specifying a metric for the amount of a proof production which 
takes place in each representation system would be essential if Weber's (2009) theoretical terms were to be meaningful.

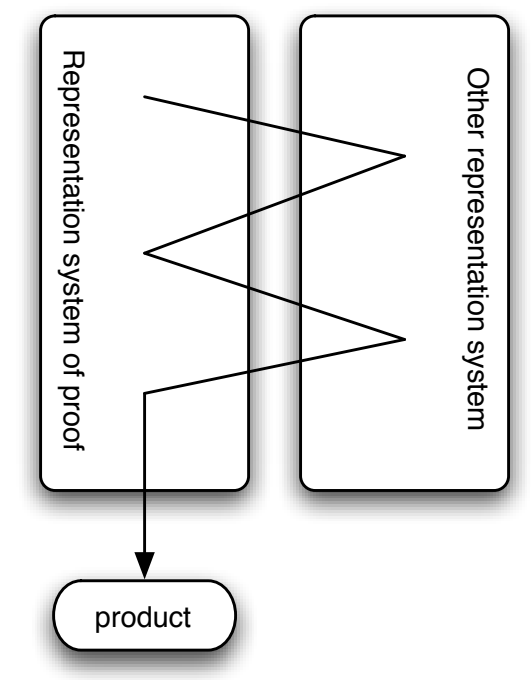

Fig. 2. A diagram indicating how a complex proof production might involve multiple translations between representation systems.

We now turn to our second rationale for preferring our characterization of semantic and syntactic proof productions. An undergraduate proof production typically starts with a to-be-proved statement ${ }^{2}$ which, inevitably, is expressed in the RSP. Consequently, any undergraduate proof production will, by necessity, involve work inside the RSP, even if it only involves reading the to-be-proved statement. Usually a successful proof production will also involve a syntactic product: a student's written product needs to be phrased within the RSP (although there are exceptions to this, including the case of counterexamples discussed above). Thus most successful proof productions in undergraduate mathematics must, by necessity, involve a lot of work within the RSP. In contrast, except in the relatively rare case of proof productions with semantic products, undergraduate proof productions are not required to involve any work outside the RSP. Inevitably, then, there is a fundamental asymmetry between the status of the RSP and other representation systems that might be involved in undergraduate proof productions.

For us, the interesting thing worth highlighting about a semantic proof production is not that it involves "much" work outside the RSP, but that it involves any work outside the RSP, and thus some translation between representation systems. To successfully work outside the RSP in undergraduate proof productions one requires the non-trivial ability to accurately translate back and forth between representation systems. It is this translation which seems to us to be fundamental to semantic proof productions, and which we

$\overline{2}$ Note that this need not be the case in research-level mathematics where, it is argued, mathematicians might compose Lakatosian 'proof-generated theorems'. 
have tried to capture in our terminology. The issue of whether semantic proof productions vary substantially in their internal structure is an interesting one, and we believe that the case of Isaac illustrates that they do. However, such differences are, at least in part, already captured by Antonini's (2006) categorization of example generation strategies, which we see as a helpful tool for distinguishing between certain types of semantic proof production that lead to a semantic product.

Both our characterization of the semantic/syntactic distinction, and Weber's (2009), are theorized on the basis of small scale collections of case-studies. But in the end, the best method of determining which of two competing frameworks to adopt is to apply them to large-scale datasets in order to determine which provides the greater analytical power and insight. We believe that our approach is sufficiently well-specified for classifying all existing published casestudies on undergraduate proof production, and that it should be useful for analyzing large-scale datasets. However, it is an open question whether or not the distinction would provide sufficient analytical power to settle the question of whether students exhibit distinct preferences during proof production (as hypothesized by, for example, Weber and Alcock 2004). The lack of studies that use large-scale datasets to investigate undergraduate proof production is, in our opinion, a serious weakness in the literature.

\section{References}

Alcock, L., Inglis, M., 2008. Doctoral students' use of examples in evaluating and proving conjectures. Educational Studies in Mathematics 69, 111-129.

Antonini, S., 2006. Graduate students' processes in generating examples of mathematical objects. In: Novotná, J., Moraová, H., Krátká, M., Stehlíková, N. (Eds.), Proceedings of the 30th International Conference on the Psychology of Mathematics Education. Vol. 2. IGPME, Prague, Czech Republic, pp. 57-64.

Goldin, G., 1998. Representational systems, learning, and problem solving in mathematics. Journal of Mathematical Behavior 17, 137-165.

Weber, K., 2009. How syntactic reasoners can develop understanding, evaluate conjectures, and generate counterexamples in advanced mathematics. Journal of Mathematical Behavior 28, 200-208.

Weber, K., Alcock, L., 2004. Semantic and syntactic proof productions. Educational Studies in Mathematics 56, 209-234.

Weber, K., Alcock, L., 2009. Proof in advanced mathematics classes: Semantic and syntactic reasoning in the representation system of proof. In: Stylianou, D., Blanton, M., Knuth, E. (Eds.), Teaching and Learning Proof Across the Grades: A K-16 Perspective. Routledge, New York, pp. 323-338. 